JLECOV

Journal of Life Economics
Volume / Cilt: 8, Issue / Sayı:3, 2021, pp. 299-307

E - ISSN: 2148-4139

URL: https://www.journals.gen.tr/jlecon

DOI: https://doi.org/10.15637/jlecon.8.3.03
Received: / Geliș: 17.05.2021

Acccepted / Kabul: 19.06.2021

\title{
Yalın altı sigma: Kavramsal bir derleme
}

\section{Lean six sigma: a conceptual framework}

\begin{abstract}
İhsan Akça $^{1}$ (D) Ferruh Tuzcuoğlu ${ }^{2}$
1 Hava Trafik Kontrolörü, Dr., Sakarya Üniversitesi Sosyal Bilimler Enstitüsü, Sakarya, TÜRKIYY, e-mail: ihsanakca@outlook.com

2 Prof. Dr., Sakarya Üniversitesi Siyasal Bilgiler Fakültesi, Siyaset Bilimi ve Kamu Yönetimi Bölümü, Sakarya, TÜRKIYE, e-mail: tuzcuoglu@sakarya.edu.tr
\end{abstract}

$\ddot{O} z$

Günümüz iş hayatında sürdürülebilir olmak, örgütlerin en büyük hedefi haline gelmiştir. Rekabet avantajı sağlayarak ürün ve hizmet sunumunda müşteri memnuniyetinin ve paydaş tatmininin sağlanması sadece özel sektörün değil kamu kurumlarının da önemli bir önceli olarak dikkat çekmeye başlamıştır. Bu kapsamda örgütler, post modern yönetim yaklaşımları uygulayarak çağın gerektirdiğgi değgişimleri başlatabilmekte, çevreyi analiz ederek proaktif ve reaktif stratejiler oluşturabilmektedir. Bu süreçte örgütlerin yararlandiğgl çeşitli yöntemler mevcuttur. Altı Sigma kavramı üretim işletmeleri başta olmak üzere pek çok işletmede müşteri memnuniyeti sağlama ve kaliteyi arttırma hususunda mükemmeliyetçiliği ve hatasızlığı savunan bir kavram olarak ele alınmaktadır. Diğer taraftan yalın üretim ve yönetim uygulamalar da faaliyetlerin gerçekleştirilmesinde ihtiyaç olmayan unsurlardan arınmış olmayı benimseme sanatıdır. Yalın Altı Sigma kavramı ise iş birimi ve süreçlere birlikte odaklanan bir felsefedir. Yalın Altı Sigma, Altı Sigmanın ve Yalın Yönetimin avantajların tek bir yönetsel teknikte ele alarak kurumsal süreçlerin tamamında mükemmeliyetçiliğgi ve yalınlığı savunmaktadır. Bu araştırmada Yalın Altı Sigma kavramının ortaya çıkmasında etkili olan Altı Sigma ve Yalın Yönetim teknikleri ele alınarak Yalın Altı Sigma'nın kuramsal olarak incelenmesi amaçlanmıştır. Altı Sigma, Yalın Yönetim ve Yalın Altı Sigma ile ilgili yapılan çalısmalara atıfta bulunulmuş, kavramın özel ve kamu sektöründe ihtiyaç duyulan alanlarda kurumların tek bir süreç ya biriminde değil tamamında benimsenip uygulanması gerekliliği sonucuna ulaşılmıştır.

Anahtar kelimeler: altı sigma, yalın yönetim, yalın altı sigma

Jel kodları: M11, M19, D20

\begin{abstract}
Being sustainable in today's business life has become the biggest goal of organizations. Ensuring customer satisfaction and stakeholder satisfaction in product and service delivery by providing competitive advantage has started to attract attention as an important priority not only for the private sector but also for public institutions. In this context, organizations can initiate the changes required by the age by applying post-modern management approaches and create proactive and reactive strategies by analyzing the environment. There are various methods used by organizations in this process. Six sigma concept is considered as a concept that advocates perfectionism and error-free in terms of providing customer satisfaction and increasing quality in many businesses, especially in production enterprises. On the other hand, lean production and management practices are also the art of embracing being free from elements that are not needed in the realization of activities. The Lean Six Sigma concept is a philosophy that focuses on business units and processes together. Lean Six Sigma advocates perfectionism and simplicity in all corporate processes by addressing the advantages of Six Sigma and Lean Management in a single managerial technique. In this research, it is aimed to examine Lean Six Sigma theoretically by considering Six Sigma and Lean Management techniques which are effective in the emergence of Lean Six Sigma concept. Referring to the studies on Six Sigma, Lean Management and Lean Six Sigma, it was concluded that the concept should be adopted and implemented in the private and public sector, not in a single process or unit, but in all institutions.
\end{abstract}

Keywords: six sigma, lean management, lean six sigma

Jel codes: M11, M19, D20

Citation/Atıf: AKÇA, I. \& TUZCUOĞLU, F. (2021). Yalın altı sigma: kavramsal bir derleme . Journal of Life Economics. 8(3):299-307, DOI: 10.15637/jlecon.8.3.03

Corresponding Author/ Sorumlu Yazar: İhsan Akça

E-mail: ihsanakca@outlook.com
Bu derginin içeriŏ Creative Commons Attribution-NonCommercial 4.0 Uluslararası Lisansı altında lisanslanmıştır. Content of this journal is licensed under a Creative Commons Attribution-NonCommercial 4.0 International License. 


\section{GİRIŞ}

Günümüzde rekabet her zamankinden daha fazladır. Günümüz rekabet ortamında işletmeler ve kuruluşlar üretim, kalite, müşteri ve kullanıcı tatmini, maliyet avantajı sağlama gibi konularda stratejiler geliştirerek sürdürülebilir olmayı hedeflemektedir (Singh ve Rathi, 2019). Bu kapsamda post modern olarak ele alınan çeşitli teknikler kullanılarak kurumsal uygulamalarının iyileştirilmesi amaçlanmaktadır. Altı sigma, yalın üretim ve yalın altı sigma çağdaş yönetim teknikleri arasında yer alan kurumsal stratejilerdir. Bu stratejiler, sadece özel sektörde değil kamu sektöründe yer alan işletme ve kurumlarda da gün geçtikçe önem arz etmeye başlamıştır. Devlet tarafından işletilen ya da kamu-özel sektör iş birliğinde üretilen ürün ve hizmetlerde çağın gerektirdiği yönetim tekniklerinin uygulanması, yenilikçi ve proaktif olunması, kaynakların verimli bir şekilde dağıtımının sağlanması, doğru yerde doğru zamanda talebe cevap verecek arzın sunulması gerekmektedir.

Özellikle hizmet ağırlıklı işlerin ön plana çıkması, bilgi işçiliğini arttırmış, ekip ve takım temelli çalışma alanlarında hatasız ve yalın süreçlerin geliştirilmesini rekabetçilik ekseninde zorunlu kılmıştır. Diğer taraftan sürdürülebilir başarı sağlama arzusunun; kaynakların korunması, israfların önlenmesi, gereksiz maliyetlerin ortadan kaldırılması, tedarik zincirinin etkinleştirilmesi ile gerçekleşmesi muhtemeldir. Bu nedenle gerek kamusal alanların yönetiminde gerek özel sektör işletmelerinde hatasızlık ve israftan kaçınma sadece bir üretim anlayışı olarak ele alınmaktan çıkmış, yönetsel anlamda da kurumların tamamına sirayet eden bir felsefe olarak değerlendirilmeye başlanmıştır. Bu felsefi akımdan hareketle altı sigma ve yalın yönetim ilişkisinin nasıl ortaya çıktığı sorusu bu makalenin kuramsal temelini oluşturmaktadır.

1987'de kalite geliştirme ihtiyacından doğan ve Motorola'nın problem çözme yaklaşımı ile tanıtımını yaptığı altı sigmada, ölç-analiz et, geliştir ve kontrol et şeklinde bir yol haritası belirlenmiştir (MAIC). 1995 yılında General Electric CEO'su Jack Welch altı sigmayı tekrar gündeme getirmiş ve altı sigma birçok işletmede kullanılmaya başlayan bir yaklaşım olmuştur. 1990'lı yıllarda sağlık, üretim, tedarik başta olmak üzere birçok işletmede altı sigma uygulamaları yapılmış ve işletmelerin milyonlarca dolar tasarruf sağladığ cıŏ̆lu ve Gözel, 2019). Asya, Avrupa ve Amerika'daki özel işletmelerin yanı sıra askeri kurumlarda da kaliteyi arttırmak amacıyla altı sigma kullanılmıştır (Snee ve Hoerl, 2003). Diğer taraftan yalın üretim bilgi temelli işlerde örneğin stokları azaltmak için zamana göre test edilmiş ilkelerin kullanılmasını sağlamıştır. İhtiyaç olunan yerde ihtiyaç duyulan zamanda ihtiyaç duyulan miktar kadar stok yapmanın israfları ortadan kaldırarak maliyet avantajı sağlayacağı gerçeğini or- taya çıkarmıştır. Bu kapsamda yalın yönetimde kitle üretimi yaparak stoklama yapmak çok fazla tercih edilmez. İtme-çekme üretim sistemleri, hücre üretimi, yalın üretim modelleri ön plana çıkmıştır. Diğer taraftan altı sigma ise toplanan verilerle istatistiksel analizler sayesinde sorun çözmeye odaklanmıştır (Snee ve Hoerl, 2003). Yalın Altı Sigma ise bu iki kavramın bir araya gelmesi ve ayrı ayrı yaratacakları değerden daha fazla bir etki oluşturarak sinerjilerini kurumsal süreçlere aktarmalarını amaçlayan bütüncül yönetsel bir tekniktir. Yalın Altı Sigma'nın son on yıldır işletmelerde uygulanmaya başladığı görülmektedir. Bu kapsamda çalışmada; altı sigma, yalın üretim-yönetim ve yalın altı sigma kavramları ele alınmış ve teorik çerçevede incelenmiştir.

\section{KAVRAMSAL ÇERÇEVE}

\subsection{Alt1 Sigma Kavramı}

Altı Sigma kalitenin geliştirilmesi amacıyla farklı sektörlerde yer alan işletmelerin ve kurumların kullandığı bir iş yönetim stratejisidir. Altı Sigma kavramı ilk olarak 1980'li yılların ortalarında Motorola mühendislerinden Bill Smith tarafından Japonya ile rekabette başarı getirmesi amacıyla ortaya atılmıştır. O dönemde özellikle elektronik endüstrisinde Japonya'nın hızlı bir atılımı mevcuttur. Japonlar, yüksek kaliteli ürünleri düşük fiyatla piyasaya arz etmektedir. Bu süreçte Amerikalı işletmeler de ürünlerini geliştirerek küresel ve yerel marketlerde daha rekabetçi olmanın yollarını aramaya başlamışlardır.1988 yılında Motorola'nın altı sigma uygulamaları nedeniyle Malcolm Baldrige Ulusal Kalite Ödülünü alması, kavramın tüm dünyadaki popülaritesini arttırmıştır (Raisinghani vd., 2005). $\mathrm{Bu}$ olaydan sonra işletmeler altı sigmayı araştırarak kendi bünyelerinde uygulamaya çalıştılar. Üretim ve endüstri işletmelerinin yanı sıra, hizmet işletmeleri de altı sigmayı uygulamıştır (Chakrabarty ve Chuan Tan, 2007). General Electric'de altı sigma metodolojisinin gelişimine katkı sunmuştur. Bu kapsamda işletmelerdeki sorunları belirleyip ortaya çıkarmayı hedefleyen ölç, analiz et, geliştir ve kontrol et aşamalarından oluşan sistemin ilk aşamasına tanımla boyutu da eklenmiştir (Ninerola vd., 2019).

Altı sigma, işletmelerin üretim kaynaklı hatalı ürünlerinin sayısını azaltmayı ve üretim süreçlerinin etkinliğini arttırmayı hedefleyen bir strateji olarak ele alınmiştır (Antony, 2006). Kwak ve Anbari (2006)'de altı sigmayı iş süreçlerindeki varyasyonun azaltılması şeklinde tanımlamışlardır. Altı sigma, \%99.99966 oranında kaliteye erişim ya da milyonda 3.4 hata olarak değerlendirilmiştir (Ninerola vd., 2019).

Altı sigmanın diğer çağdaş yönetim tekniklerinden (yalın yönetim-toplam kalite yönetimi) farkı maliyetlere ve maliyetleri düşürücü tasarruflara odaklanmasıdır. Hatasız, güvenilir ürün ve hizmetlerin ortaya 
çıarılması sayesinde altı sigma, kar marjlarını arttırır ve müşteri tatmini sağlar (Karoutve Awasthi,2017).

Altı sigma, müşteriler tarafından kusur ve yanlış olarak tanımlanan hataların kaynağının elimine edilmesi, sapmaları azaltacak şekilde süreçlerdeki gereksiz faaliyetlerin atılması, istatistiksel olarak da desteklenen örgütsel etkinlik ve gelişimde milyonda 3.4 hataya denk gelecek şekilde yapılanmanın tasarlandığ1 güçlü, sistemli, disiplinli, sorun çözücü iyi organize edilmiş ve proaktif, devamlılık gösteren süreç geliştirme stratejisidir (Duru, Koç ve Taş, 2011; Ninerola vd., 2019). Bununla birlikte Altı Sigma milyonda 3.4 hata taramasını kabul ederken, son yıllarda gündeme gelen 7 Sigma ise milyonda 0.019 hatayı hedeflemektedir (Panagopoulos, Atkin ve Sikora, 2016).

Kwak ve Anbari (2006), altı sigma aşamalarını aşağıdaki gibi ele almışlardır:

\section{Tanımla (Define)}

-Müşterinin gereksinimlerini ve beklentilerini tanımlama,

-Proje sinırlarını tanımlama,

-İş akışını haritalayarak süreci tanımlama.

\section{Ölçme (Measure)}

- Müşterinin ihtiyaçlarını karşılamak için süreci ölçme,

- Bir veri toplama planı geliştirme,

- Sorunları ve eksiklikleri belirlemek için verileri toplayın ve karşılaştırma.

\section{Analiz Etme (Analyze)}

-Kusurlarin nedenlerini ve varyasyon kaynaklarinı analiz etme,

-Süreçteki varyasyonları belirleme,

- Gelecekteki iyileştirmeler için fırsatları önceliklendirme.

\section{Geliștirme (Improve)}

- Değişiklikleri ortadan kaldırmak için süreci iyileştirme,

-Yaratıcı alternatifler geliştirme ve gelişmiş planlar uygulama.

\section{Kontrol Etme (Control)}

-Müşterilerin gereksinimlerini karşılamak için süreç varyasyonlarını kontrol etme,

-İyileştirilmiş süreci izlemek ve kontrol etmek için bir strateji geliştirme,

- Sistemlerin ve yapıların iyileştirmelerini uygulama.
Altı sigma, Deming felsefesi, toplam kalite yönetimi gibi kavramların çatısı altında popülarite kazanmış bir kavramdır. Altı sigma, işletme süreçlerindeki sapmaları azaltan istatistiksel düşüncedir (Chakravorty, 2009). Antony ve melektaşları'na (2008) göre altı sigma, işletmelerde süreç performans karakteristiklerine odaklanarak hata ve kusurların tanımlanması ve elimine edilmesini amaçlayan bir unsurdur. Bu bakış açısıyla altı sigma, kalitenin devamlılığının sağlanması hususunda kritik düzeyde öneme sahiptir.

Motorola işletmesi altı sigmayı sadece hatasız bir ürün üretmek için değil, aynı zamanda şirketler genelinde kusurları ortadan kaldırmak için ele almıştır. Altı Sigma, Yunan terminolojisine dayanan sigma $(\sigma)$ dan türemiş ve istatistik biliminde varyasyonu-standart sapmayı ifade eden strateji haline gelmiştir (Rathi vd., 2016).

Altı sigma kalite kontrol ölçümü amaciyla ortaya çıkarılan ancak daha sonra işletmenin tamamını geliştiren bir unsur haline gelmiştir. Aslında altı sigma felsefesini benimseyen işletmelerin de amacı bu olmalıdır. Sadece üretimin değil, üretim-hizmet sunumu dahil tüm örgütsel süreçlerin altı sigma ilkeleri ile bütünleşmesi kusursuz sürdürülebilirlikte önem arz etmektedir. Altı sigmanın Motorola işletmesinde doğuşunda Deming'in başarıyı arttırmada ele aldığı ve sapmaları ortadan kaldırmanın bir yolu olarak hazırladığı süreç sapmaları modelinin Mikel Harry tarafından Motorola fabrikasına adapte edilmesiyle gerçekleştiği bilinmektedir. Bu kapsamda altı sigma, mükemmele erişmekle birlikte sürekli iyileşme ve gelişme olarak da değerlendirilmiştir. Altı sigmanın sigması, süreçlerdeki ortalamalardan sapan standart sapmaları temsil etme derecelerinden biridir. Müşteri ihtiyaç ve gereksinmelerini karşılamayan her şey hata ve kusur olarak ele alınır ve altı sigmanın analiz içeriğini oluşturur (Ertürk, 2009).

Altı sigma toplam kalite yönetimi ile çok yakından ilişkilendirilmiştir. Toplam Kalite Yönetimi de örgüt içerisinde tüm çalışanları ve süreçleri kapsayacak şekilde kalite iyileştirilmesi felsefesine dayanmaktadır. Buna karşın Toplam Kalite Yönetimi her işletmede istenen düzeyde görünür varlıklar da olumlu yönde değişimi tetiklemediği için işletmeler farklı stratejileri kullanarak kaliteyi ve örgütsel çıktıları geliştirmeyi amaçlamıştır (Laureani ve Antony, 2012). Motorola başta olmak üzere somut sonuçların elde edilmesi diğer kuruluşların da altı sigmaya yaklaşımını etkilemiştir. General Electric büyük bir kuruluş olduğu için üretimden elde edilen somut çıtılar, finansal kurumlar başta olmak üzere farklı birimlere kanalize edilmiştir. Bu iş modeli iş piyasalarında dikkat çekmiştir. Bu doğrultuda Altı Sigma, Ticari Kalite olarak anılmaya başlamış ve giderek itibar kazanmıştır. Ayrıca CEO Jack Welch (General Electric) bu süreçte tüm çalışanları altı sigmanın bir parçası haline getirme hu- 
susunda onları yönlendirerek değişimin içinde aktif rol almalarını sağlamıştır.

3M, Ford, American Express, Honeywell gibi işletmeler altı sigma uygulamaları ile kurumsal performanslarını yükseltmişlerdir.1994'te Allied Signal'in CEO'su Larry Bossidy de altı sigmayı; yüksek seviyede sonuçlar üretmek, iş süreçlerini geliştirmek, kültürü değiştirmek ve çalışan becerilerini geliştirme temelinde bir iş girişimi olarak tanıtmıştır (Schroeder vd., 2008).Bununla birlikte Motorola, Samsung, Honeywell, Sony altı sigmayı kalite arttırıcı bir araç olarak kulanmış ve örgütün tamamında işlevsel hale getirmeye çalışmışlardır. Uluskan (2017), Türkiye'de gerçekleşen altı sigma uygulamalarının yaklaşık \%5'inin hizmet sektöründe gerçekleştiğini bulgulamıştır.

\subsection{Yalın Üretim-Yönetim}

Yalın yönetim kavramı da Altı Sigma'nın gelişimi gibi bir süreçte ortaya çıkmıştır. Yalın yönetim kavramı, Toyota Üretim Sisteminde belirlenmiş ve Toyota Performans Sistemi olarak da anılmıştır (TPS) (Bayer, 2020; Womack ve Jones, 2003). Elbette Toyota'nın bu yaklaşımı II. Dünya Savaşı sonrasında Amerika'da yapilan incelemeler sonucunda Japonya ve Batının kıyaslanması ve bu kıyaslama sonucu elde edilen verilerin kendi süreçlerine kültürel uyum ile aktarılması sonucu ortaya çıkmıştır. Bu kapsamda Toyota Performans Sistemi'nin felsefesinin dayandığı yalınlık, temelde Henry Ford'un montaj hattı incelemelerine ve Frederick Taylor'un bilimsel yönetim ilkelerine kadar dayanmaktadır (Womack ve Jones, 2003). Yalın yönetim, üretim süreçlerinde (ürün-hizmet); katma değer yaratmayan ve israfa yol açan tüm uygulamaları (insan hareketi dahil) ortadan kaldırmayı hedefleyen çağdaş bir yönetim tekniğidir (Singh ve Rathi, 2019). Bilimsel olarak ilk defa yalın üretim kavramının da Krafcik (1988) tarafından ele alındığı kabul edilmektedir (Antony vd., 2017).

Yalın üretim, katma değersiz parametrelerin ve israfın ortadan kaldırılmasına odaklanmıştır. Yalın üretimde israfa sebep olan yedi parametre; ulaştırma, envanter, hareket, aşırı işleme, aşırı üretim, bekleme ve kusurlardır (Wong vd, 2014). Yalın üretime yönelik araç ve teknikler, Kanban sistemi, 5S, neden ve sonuç (C\&E) analizidir. Yalın üretimin hatta daha geniş kapsamlı olarak ele alındığında örgütlerdeki yalın yönetim felsefesinin karşılaştığı en önemli sorunsal unsur, değişime yönelik kültürel dirençtir. Bu nedenle paydaş perspektifinde yalınlık olgusunun iyi benimsenmesi ve maliyet avantajı sağlayarak israfları ortadan kaldıracağına yönelik inancın olgunlaşması gerekmektedir (Singh ve Rathi, 2019).

Ertürk (2009) yalın olma kavramını faaliyetlerin yürütülmesinde gerçekten ihtiyaç duyulmayan her şeyden arınmış olmak olarak ele almıştır. Yazara göre, yalın olma sadece üretimde değil tüm örgütsel faaliyetlerde yalınlaşmayı savunmakta ve yalın yönetim felsefesini ortaya çıarmaktadır. Bu kapsamda organizasyonun yalın bir organizasyon olarak değerlendirilmesi için daha az girdi ile daha az zamanda daha yüksek kaliteli mal ve hizmet sunmak amaciyla işletme içerisinde gereksiz tüm aşamaların ortadan kaldırılması ve geriye kalan süreçlerin devamlı bir akış düzenine konulması gerekmektedir (Ertürk, 2009). Yalınlaşma sadece ürün ve hizmet süreçlerinde değil, çalışanlar perspektifinde de iyi algılanarak çok çalışmak, az tüketmek, birlik ve beraberlik sağlamak, problem çözme odaklı olmak, mesleki becerileri arttırmak gibi yaklaşımlar ile desteklenmelidir (Ertürk, 2009).

Yalın üretim yöntemi ise 1950 yılında Taichi Ohno tarafından Japonya Toyota firmasında hayata geçirilmiştir. Tam zamanında üretim, kalite yaklaşımı, sıfır stok, sıfır hata ve yalın örgütlenme gibi unsurlar yalın üretimin temel taşlarıdır (Efil, 2010). Özçelikel (1994)'e göre ihtiyaç duyulmayan şeylerden kurtulmak yalınlığın temel felsefesini oluşturmaktadır. Yalınlık, Japon felsefesinden beslenen bir sistemdir. Mottainai anlayışı sahip olunan her şeyin emanet olduğunu tanımlarken, bu emanetlerin en uygun şekilde kullanılmaması ise Muda'dır. Kısaca yalınlaşma israf olarak da tanımlanan Mudaların ortadan kaldırılmasıdır (Ertürk, 2009). Sanayi Devrimi sonrasında klasik yönetim yaklaşımı prensiplerine uygun olarak kitlesel üretim hacimleri artmış ve belirli zaman sonra mamullerde israflar, hatalar gözlemlenmiştir. Fordist üretimdeki mudalar-hatalar-fireler Japon bilim insanları tarafından geliştirme ve iyileştirmeler ile kendi markalarında ve ürünlerinde daha az gözlemlenir hale gelmiş ve Asyalı birçok işletme rekabette yenik düştügü Batı'nın maliyet ve kalitede önüne geçmeyi başarmıştır.

Yalınlık, ürün ve hizmet üretirken en düşük maliyetle hızlı olmayı amaçlayarak verimliliğe odaklanır (Gök ve Arıc1, 2016). Yalın üretim felsefesi ise, yalın düşünmeye dayanır ve üst düzey desteğinden alt düzeye kadar kademelendirilmesi gerekmektedir (Antony vd., 2017). Bu doğrultuda ürün-hizmet sunumunda örgütsel süreçlere kadar yalın yönetimi benimseyen organizasyonların özellikleri aşağıdaki gibi sıralanmaktadır (Efil, 2010):

-Uzmanlık dışında kalan faaliyetler işletme dışı kuruluşlara devredilmektedir.

-Yetkinin tabana yayılması ile basık bir örgüt yapısı mevcuttur. Az kademeli örgüt yapısında ana süreç-ana müşteri ve ana ürün hatları şeklinde iş modelleri oluşturulur. Bu süreç sistemlerinde müşteri ve ürün hatları ayrı birer işletme gibi faaliyetlerini yürütmektedir. Bu kapsamda hat içerisinde kaliteden mühendisliğe birçok işlemin ayrı olarak yürütüldüğü görülmektedir. 
-Yönetim, çalışanları yönetmek yerine yönlendirmeyi ve buna uygun çalışma atmosferini sağlamayı hedefler.

-İşlerin tasarımında güvenilirlik ve basitlik amaçlanmaktadır.

\subsection{Yalın Altı Sigma}

Yalın Altı Sigma (YAS), yalın üretim ve altı sigma kavramlarının bir araya gelmesi ve ayrı ayrı yaratacakları değerden daha fazla bir etki oluşturarak sinerjilerini işletme-kurum süreçlerine aktarmalarını amaçlayan bütüncül yönetsel bir tekniktir. YAS, süreç yönetimi ve süreç mükemmeliyetçiliği açısından güçlü bir stratejidir. YAS ile mükemmel hale gelmesi beklenen süreçler, ürün ve hizmet sunumunda hataları ve sapmaları azaltarak, işletmenin rekabet gücünü ve müşteri bağlılığını arttırmaktadır (Snee, 2010).

Altı sigma uygulamalarını projelendirerek gerçekleştiren işletmeler başarılı olmaktadır. Disiplin çerçevesinde altı sigmayı ele almayan işletmeler ise başarı yakalayamazlar (Kumar vd., 2009). Yalın altı sigma, altı sigma ve yalın üretim kavramlarının bir araya gelmesi ve bu birleşim ile daha iyi sonuçların elde edilmesi beklentisinden doğmuştur. 1980'lerde Altı Sigma Motorola tarafından geliştirilmiştir ve 2000' li yılların başında yalın (Lean) metodolojisi ile birleştirilmiştir.

Altı Sigma'nın projelendirilme aşamasında verimlilik artışı ve maliyetlerin azaltılmasının yanı sıra marka imajının güçlendirilmesi de mevcuttur. Yalın üretim yaklaşımı da israfları ve gereksiz işlemleri ortadan kaldıracağından daha sağlıklı bir çalışma ortamının tasarlanmasında katkı sunulmaktadır. Bu kapsamda yalın altı sigma doğru uygulandığında çalışan motivasyonu da artış gösterecektir (Dahlgaard ve Dahlgaard, 2003). Bu beklentilerden hareketle birçok işletme altı sigma ve yalın üretim-yönetim yaklaşımlarını birleştirmeye başlamıştır. Yalın Altı Sigma sayesinde israfların ayıklanması ve bununla beraber kalitenin güçlendirilmesi hedeflenmiştir. Böylece kurumsal uygulamalarda ve süreçlerde hataya dönüşmeden önce kusur oluşum riskini belirlemek ve önlemek hususunda süreç iyileştirmesi yapılmaktadır (Antony vd., 2006; Ghane, 2014).

Yalın metodoloji temel olarak süreçler arası bilgi akışına, altı sigma ise süreçler içindeki iyileştirmeye odaklanır. Bu nedenle, Yalın Altı Sigma, işletme perspektifi açısından kapsamlı bir stratejidir. Yalın Altı Sigma işletmelerin müşteri isteklerini etkin bir şekilde tanımasını sağlar ve değişkenliği ortadan kaldırır. Bununla birlikte üretim dahilinde katma değeri olmayan tüm faaliyetleri azaltır (Singh ve Rathi, 2019).
Şekil 1: Yalın Altı Sigma

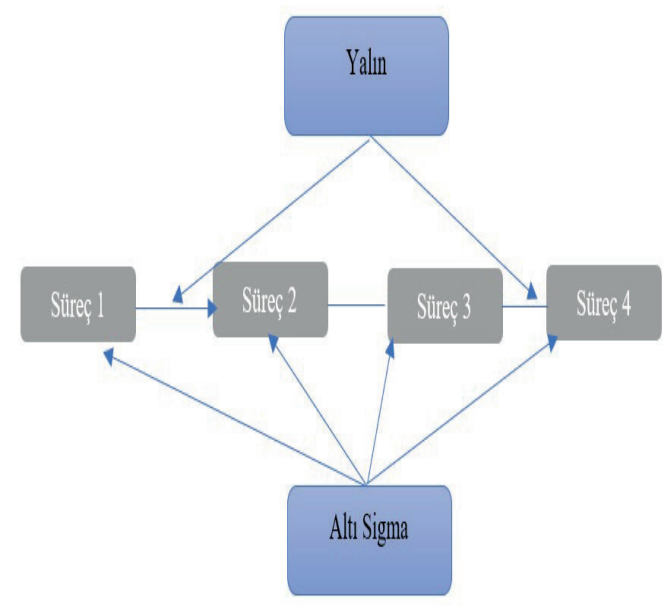

Kaynak: (Singh ve Rathi, 2019)

Şekil 1'de görüldüğü gibi yalınlık, süreçler arasındaki bilgi akışlarındaki israfları ortadan kaldırma felsefesine, altı sigma ise süreç aşamalarına değer katarak kaliteyi arttırmaya odaklanır. Yalın altı sigma uygulamalarının lojistikten eğitim sektörüne, bankac1lık faaliyetlerinden kimya endüstrisine kadar çok kapsamlı alanda mevcut olduğunu söylemek mümkündür (Doğan ve Demiral, 2008; Singh ve Rathi, 2019).

Altı sigma ve yalın üretim-yönetimin birleşimi şirket evliliği gibi bir etki yaratmak amacıyla oluşturulmaktadır. Bu kapsamda Yalın Altı Sigma, toplam kalite yönetimi, deming felsefesi, istatistiksel süreç kontrolü ile ilişkilendirilebilecek bir yaklaşımdır (Laureani ve Antony, 2012). Snee (2010) ise yalın altı sigmayı; normal şartlardan daha yüksek düzeyde müşteri memnuniyeti ve performans ile sonuçlanan, bu çıtıların elde edilmesinde süreçleri güçlendiren bir iş stratejisi ve metodolojisi olarak tanımlamaktadır. Bununla birlikte, örgütsel kapasitenin geliştirilmesi, üretim maliyetlerinin düşürülmesi, kalitenin iyileştirilmesi ve paydaşlar açısından değerin en üst düzeye çıkarılması amaçlanmaktadır (Laureani ve Antony, 2012).

Hem Altı Sigma hem de yalın üretim-yönetim, tek uygulandıklarında da muazzam sonuçlar üretmiştir ancak çeşitli kısıtlarının olması bir araya gelmelerini hızlandırmıştır. İki kavramın entegrasyonu uzmanların ilgisini çekmiştir (Antony vd., 2017). Örneğin George (2002) yalın yaklaşımının yoğun veri analizi ve gelişmiş istatistiksel yöntemler gerektiren karmaşık sorunları çözmek için pek uygun olmadığını ifade etmiştir. Diğer taraftan altı sigmanın da her sorun çözümünde ve proje işinde çok fazla veriye gereksinim duyduğunu, bu durumun basit sorunlar için kullanışlı olmayacağı belirtilmiştir. Bu kapsamda iki yöntemin birleşimi mevcut olan araçların yeni süreçlere ve yol haritalarına adapte edilmesiyle başarı yakalama potansiyelini arttırmıştır (Antony vd., 2017). 
Yalın Altı Sigma'nın örgütlere sunduğu avantajlar ile yapılanmasında karşılaşılan sorunlar aşağıda ele alınmaktadır (Singh ve Rathi, 2019; Albliwi vd.,2015; Guerrero vd., 2017; Gerger ve Firuzan, 2010).

Tablo 1: Yalın Altı Sigma Avantajları ve Karşılaşılan Sorunlar

\begin{tabular}{|c|c|}
\hline Avantajlar & Karşılaştı̆̆ı Sorunlar \\
\hline $\begin{array}{l}\text { - Stok tutma miktarında } \\
\text { azalma (gereksiz stok } \\
\text { maliyetlerini ortadan } \\
\text { kaldirır). } \\
\text { - Kaliteyi arttıracağından } \\
\text { kalitesizlik maliyetlerini } \\
\text { azaltır. }\end{array}$ & $\begin{array}{l}\text { •İzlenecek bir yol } \\
\text { haritasının olmaması, } \\
\text { •YAS hakkında yayın- } \\
\text { lanmış vaka çalışma- } \\
\text { larının kısıtlılığı, }\end{array}$ \\
\hline $\begin{array}{l}\text { - Müşteri tatmini ve bağ- } \\
\text { lilığını yükseltir. } \\
\text { •Çevrim süresini azaltır. } \\
\text { • Hatasız süreçler geliş- } \\
\text { tirir. }\end{array}$ & $\begin{array}{l}\text { - Sertifikasyon için } \\
\text { evrensel olarak kabul } \\
\text { edilmiş bir standart } \\
\text { yapının olmayışı, }\end{array}$ \\
\hline $\begin{array}{l}\text { • Üretim ve hizmet } \\
\text { sunumunu güçlendirir. }\end{array}$ & $\begin{array}{l}\text { - Uygun bir çerçevenin } \\
\text { olmaması, }\end{array}$ \\
\hline $\begin{array}{l}\text { - Çalıșan performansını } \\
\text { arttırır. }\end{array}$ & •Uzmanlık eksikliği, \\
\hline $\begin{array}{l}\text {-Küresel pazarlarda re- } \\
\text { kabet edebilme yetkinli- } \\
\text { ği oluşturur. }\end{array}$ & $\begin{array}{l}\text { •Veriye erişememe, } \\
\text { •Örgütsel kültür, }\end{array}$ \\
\hline $\begin{array}{l}\text { - Alt düzeyde tasarrufları } \\
\text { arttırarak üst düzeyde } \\
\text { karlılığ yükseltir. }\end{array}$ & •İletişim sorunlarıdır. \\
\hline
\end{tabular}

Tablo 1'de görüldüğü gibi Yalın Altı Sigma'nın avantajları; geliştirilmiş operasyonel verimlilikler, düşük maliyet, azaltılmış hata, geliştirilmiş hizmet kalitesi, katma değerli olmayan adımların süreçlerden çıkartılması, gecikmelerde düşüş, iyileştirilmiş çevrim süresi, şikayetlerde azalma ile müşteri ve çalışan tatmininin artmasıdır. Diğer taraftan, Yalın Altı Sigma, büyük veya küçük herhangi bir kuruluşta uygulandığında, uygulayıcıları ve uzmanları tarafından zorluklar ve kısıtlılıklar da ortaya çıkmıştır. Bunlar; kaynak eksikliği, istatistiksel yöntemlerle çalışma zorluğu, Yalın Altı Sigma'nın işe yarayacağına dair inanç eksikliği, Yalın Altı Sigma'nın faydaları hakkında farkındalık eksikliği, Yalın Altı Sigma için veri toplamadaki zorluklar, sorunlu çalışanlar, liderlik eksikliği, eğitim programı eksikliği, sürdürülebilirlik eksikliği, çalışmaya katılım problemleri, yanlış proje seçimi, yanlış iyileştirme aracı seçimleri, vizyonun net belirlenmemesi, kültür değişikliğine karşı direnç, performans ölçüm sistemi eksikliği, zayıf iletişimdir. Bununla birlikte kişiler arasında koordinasyon eksikliği, çalışanların ve yönetimin değişime direnci, ekip çalışmasına güven eksikliği, farklı müşteri segmentlerinin görüşlerine yönelik anlamlandırma eksikliği de Yalın Altı Sigma uygulamalarının başarısızlıkla sonuçlanmasına neden olabilecek etmenler arasında yer almaktadır (Singh ve Rathi, 2019).
Yalın Altı Sigma (YAS), çeşitli kısıtlara karşın örgütlerde yenilikçilik, performans artışı, tasarruf ve kalite iyileştirilmesi gibi olumlu çıtıların elde edilmesini sağlamıştır. Örneğin Xerox, YAS uygulamaları ile inovasyon ekiplerini bir araya getirerek etkileyici sonuçlar elde etmiştir. İşletmelere doğru uygulandığında milyonlarca dolar tasarruf sağlama imkânı veren YAS, kendi içerisinde yenilikçi ve yaratıcı düşünce biçimini de barındırmaktadır. YAS'ın tüm aşamalarında her aşamaya nasıl yaklaşılacağını belirlemek için önemli ölçüde yaratıcı düşünceye ihtiyaç vardır. Bu kapsamda YAS'ın Schumpeter'in yıkıcı yenilik yaklaşımından da destek aldığını söylemek mümkündür. Sürdürülebilir başarı ve kalite için kusurlara ve israfa yol açan geleneksel uygulamaların ortadan kaldırılması yıkıcı yenilik akımı ile gerçekleşmektedir. Antony ve meslektaşları (2014) da İngiltere'de YAS ve ürün-süreç-hizmet yeniliği ilişkisini ortaya çıkarmak için yürüttükleri araştırmalarında YAS girişimleri bulunan örgütlerin yenilik yetkinliklerinin daha fazla olduğunu ortaya çıkarmışlardır. Byr (2020) yürüttüğü araştırmasında yalın yönetimin çalışan performansını istatistiksel olarak anlamlı bir şekilde etkilediğini saptamıştır. Topçu, Doğan ve Doğan (2018) yükseköğretim kurumlarında altı sigma uygulamalarını kalite ile ilişkilendirilecek önemli bir yöntem olduğunu belirtmişlerdir. Yılmaz Yalçıner ve Günday (2020) bankacılık sektöründe YAS uygulamasını analiz etmiştir. Diğer taraftan, sağlık sektöründe yalın yönetim ve yalın üretim alanında yapılan çalışmalarda kamu kurumlarında da yalınlaşma yönünde çalışmaların dikkat çektiğini söylemek mümkündür. Yapılan çalışmalarda gereksiz işlemlerin azaltılması, hizmet kalitelisinin ve performansın arttırılması yönünde hedeflerin ön plana çıktı̆̆1 görülmektedir. (Aslan ve Pekcan, 2020; Dağcı ve Aslan; 2020). Bu yaklaşımlar kurumlarda yalın liderlik kavramını ortaya çıkarmaktadır. Liderlerin desteği, örgüt kültürünün değişime uyarlanması, çalışan katılımının sağlanması, paydaş amaçlarının bütünleştirilmesi gibi birçok amaç ancak yalın ve altı sigma felsefelerini benimsemiş ve entegre etmiş bir liderin varlığında ortaya çıacak ve örgütün sürdürülebilir performans sağlamasına zemin hazırlayacaktır. Bununla birlikte Apilioğulları (2020) YAS uygulamalarında Endüstri 4.0 teknolojilerinin kullanılmasının da birtakım faydaları olduğunu belirtmiştir. Bu kapsamda bilgi çağı olarak adlandırılan günümüzde bilgi ve iletişim teknolojileri temelli otomasyon sistemleri, yapay zekâ uygulamaları gibi pek çok yeniliğinin üretim sektörlerinde olduğu kadar hizmet sektörlerinde de kullanılabilir olması gerekliliği, YAS gibi post modern yönetim uygulamalarının başarısını arttıracaktır.

\section{SONUÇ}

Günümüzün rekabetçi iş hayatında kalite gelişimi ve sürekli iyileştirme, sektör fark etmeksizin örgütler için önemli birer iş stratejisi haline gelmiştir. Eğitim 
işletmesi, sağlık kuruluşu, üretim işletmesi, finans kuruluşu gibi farklı piyasalarda ürün ve hizmet sunan örgütler varlıklarını devam ettirmek ve rekabet avantajı sağlamak için çağdaş yönetim uygulamalarını kullanmaktadır. Bu kapsamda kökleri altı sigma ve yalın üretim-yönetim yaklaşımlarına dayanan Yalın Altı Sigma son on yıldır örgütlerin dikkatini çekerek kendine uygulama alanı oluşturmuştur.

Yalın Altı Sigma'nın başarılı bir uygulama alanına sahip olarak örgütsel performansı arttırması için kararlı bir liderlik profili gerekmektedir. Bu süreçte liderlik, kaynakları, kaynakların dağıtımını etkin bir şekilde gerçekleştirir, güçlü bir iletişim ağı kurar ve inisiyatif göstermesi gerektiği durumlarda davranış biçimlerini uygun şekilde belirler. Bununla birlikte yetenekli kişilerin Yalın Altı Sigma girişimine atanması da önem arz etmektedir (Doğan ve Demiral, 2008). Ayrıca, destekleyici bir altyapının mevcut olması da Yalın Altı Sigma başarısına olumlu yönde katkı sağlayacaktır. Bu unsur kuşak sistemi ile ilişkilendirilmiştir (Siyah Kuşak-Yeşil Kuşak-Sarı Kuşak gibi). Yalın Altı Sigma şampiyonlarının (çalışan-üst düzey) aktif katılımı, girişimin başarı ile sürdürülmesini kolaylaştıracaktır (Öztürk, 2017). Proje seçimi, önceliklendirme, raporlama ve takip sistemi de Yalın Altı Sigma uygulaması üzerinde etkili olacaktır. Üst yönetimini ilgisinin devamlılığının sağlanması için örgütlerde ilk birkaç yılda gerçekleşmesi planlanan Yalın Altı Sigma projelerinin doğru seçilmesi ve sürecin 3-6 yıl içinde tamamlanması gerekmektedir. Böylece ilgi ve memnuniyet yeni uygulamalara hevesi arttıracaktır. Son olarak Yalın Altı Sigma projelerinin gerçekleştirilmesi hususunda örgüt içerisinde kültürel değişim ihtiyacı varsa bu en başta doğru bir şekilde ortaya konulmalıdır. Aksi takdirde ilerleyen aşamalarda kültürel değişim olgusu girişimin başarısını azaltmanın yanı sıra ortadan kalkmasına da sebep olabilmektedir (Brewer ve Eighme, 2005).

Yalın Altı Sigma örgütlerin kalite iyileştirmesi ya da israflardan kaçınma isteklilikleri ile bağlantılı olarak gelecek trendlere göre gelişim gösterebilecektir. Bu kapsamda küreselleşme ve ilişkili pazar baskıları, tüketicilerin artan kalite iyileştirmesi beklentisi, hatalar ve kusurların sosyal medya başta olmak üzere çeşitli çevrimiçi platformlarda müşteriler tarafından kamuoyu ile paylaşılması, bilgi ve iletişim teknolojilerinin gelişimi, teknolojik gelişmelerin ortaya çıkaracağ1 karmaşık sorunların çözülme ihtiyacı gibi faktörler nedeniyle Yalın Altı Sigma uygulamalarına yönelik talep artış gösterecektir. Diğer taraftan, gerek özel sektör gerekse kamu kurumu olarak işletmelerin Yalın Altı Sigma girişimlerini gerçekleştirirken dikkat etmesi gereken hususlar; YAS'ın eğitim sistemleri ile entegrasyonunun sağlanması, stratejik düşüncenin daha fazla kullanılması, bütünsel iyileştirmeye odaklanarak organizasyonel gelişimin arttırılması, istatistiksel yöntemler kullanılarak görev açısından kritik problemlerin tanımlanması ve çözülmesi, veri madenciliğinden faydalanılması, projelerde nitelikli ve uyumlu personel ile çalışılması ve iyileştirme çalışmalarının sürdürülebilirliğinin sağlanması şeklinde listelenmektedir (Antony vd., 2017). Bu açıdan bakıldığında YAS'ın başarılı bir şekilde gerçekleştirilmesi için ortamın hazır olması, değişime direncin yönetilmesi ve uygulamaların ana felsefesinin üst yönetimden alt birimlere kadar benimsenip tüm alanlarda desteklenmesi ve kabul edilmesi gerekmektedir. İlerleyen çalışmalarda Türkiye'de Yalın Altı Sigma uygulamaları ile ilgili vaka çalışmaları ve ampirik araştırmaların yapılması post-modern yönetim teknikleri ile bireysel ve örgütsel sonuçlar arasındaki güçlü ilişkilerin daha objektif bir şekilde bilime katkı sunmasına olanak taniyacaktır.

\section{KAYNAKÇA}

ALBLIWI, S.A., ANTONY, J. \& LIM, S.A.H. (2015). A Systematic Review of Lean Six Sigma for the Manufacturing Industry. Business Process Management Journal. 21(3): 665-691.

ANTONY, J., KUMAR, A., \& BANUELAS, R. (2006). World Class Applications of Six Sigma. Routledge.

ANTONY, J., KUMAR, M., \& LABIB, A. (2008). Gearing Six Sigma into UK Manufacturing SMEs: Results from a Pilot Study. Journal of the Operational Research Society. 59(4): 482-493.

ANTONY, J., RODGERS, B. \& CUDNEY, E.A. (2017). Lean Six Sigma for Public Sector Organizations: is it a myth or reality?. International Journal of Quality \& Reliability Management. 34(9): 1402-1411.

APİLiOĞULLARI, L. (2020). Yalın Altı Sigma ve Endüstri 4.0 Entegrasyonu ile Kalite İyileştirme Vaka Çalışması. Anemon Muş Alparslan Üniversitesi Sosyal Bilimler Dergisi. 8(5): 1497-1504.

ASLAN, S., \& PEKCAN, G (2020). Hastanelerde Yalın Yönetim Uygulamaları: Gümüşhane Acil Servisi Değerlendirmesi. ERÜ Să̆lık Bilimleri Fakültesi Dergisi. 7(1): 1-12.

ATMACA, H. E., \& GİRENES, S. Ş. (2009). Literatür Araştırması: Yalın Altı Sigma Metodolojisi. Gazi Üniversitesi Mühendislik Mimarlık Fakültesi Dergisi. 24(4): 605-612.

BALCİOGLU, Y. S., \& GOZEL, A. (2019). Alternatif Yönetim Yaklaşımlarından: Yalın Altı Sigma. PressAcademia Procedia. 9(1): 105-108. 
BAYAR, M. (2020). Yalın Yönetim Anlayışının, Çalışanların Görev Performansına Etkilerine Yönelik Bir Araştırma. İşletme Araştırmaları Dergisi. 12(2): 1984-2001.

BREWER, P. C., \& EIGHME, J. E. (2005). Using Six Sigma to Improve the Finance Function. Strategic Finance. 86(11), 27-33.

CHAKRABARTY, A. \& TAN, C. K. (2007). The Current State of Six Sigma Application in Services. Managing Service Quality: An International Journal. 17(2):194-208.

CHAKRAVORTY, S. S. (2009). Six Sigma Programs: An Implementation Model. International Journal of Production Economics. 119(1): 1-16.

DAĞCI, A., \& ASLAN, E. (2020). Sağlık Sektöründe Yalın Üretim Uygulamasi: Tokat İlinde Bir Devlet Hastanesi Örneği. Hacettepe Sağllk İdaresi Dergisi. 23(4): 623-638.

DAHLGAARD, J. J., \& DAHLGAARD-PARK, S. M. (2006). Lean production, six sigma quality, TQM and company culture. The TQM magazine. 18(2), 263-281.

DOĞAN, S., \& DEMIRAL, Ö. (2008). Yalın Yöntemler ve Altı Sigmayı İçeren Bütünleşik Bir Yaklaşım: Yalın Altı Sigma. Atatürk Üniversitesi İktisadi ve İdari Bilimler Dergisi. 22(1): 343-366.

DURU, N., KOÇ, H., \& TAŞ, Y. (2011). İşletmelerde Hatasızlığa Yönelim, Altı Sigma ve Hata Türü Etkileri Analizi. Düzce Üniversitesi Ormancilı Dergisi. 7(1): 5667.

EFIL, İ. (2009). Yönetim ve Organizasyon, 10. Baskı, Bursa: Alfa Aktüel Yayınları.

ERTÜRK, M. (2009). İşletmelerde Yönetim ve Organizasyon. İstanbul, Beta Yayıncılık.

GERGER, A., \& FİRUZAN, A.R. (2010). Yalın Altı Sigma Projelerinin Başarısız Olma Nedenleri. Journal of Yaşar University. 50(20): 3383-3393.

GEORGE, M.L. (2002). Lean Six Sigma: Combining Six Sigma Quality with Lean Speed.Mc Graw-Hill.

GHANE, K. (2014). A model and system for applying Lean Six sigma to agile software development using hybrid simulation. In 2014 IEEE International Technology Management Conference (pp. 1-4). IEEE.

GÖK, M. Ş., \& ARICI, T. (2016). Yalın Yönetim Sistemlerinde Alternatif Yaklaşım: Dinamik Kalite Yönetim Sistemi. Kocaeli Üniversitesi Sosyal Bilimler Dergisi. 31: 135-143.

GUERRERO, J. E., LEAVENGOOD, S., GUTUÉRREZ-PULIDO, H., FUENTES-TALAVERA, F. J., \& SILVA-GUZMÁN, J. A. (2017). Applying lean Six Sigma in the Wood Furniture İndustry: A Case Study in a Small
Company. Quality management journal. 24(3): 6-19.

KAROUT, R. \&AWASTHI, A. (2017). Improving Software Quality Using Six Sigma DMAIC-Based Approach: A Case Study. Business Process Management Journal. 23(4): 842-856.

KRAFCIK, J. F. (1988). Triumph of the Lean Production System. MIT Sloan Management Review. 30(1): 41.

KUMAR, M., ANTONY, J.\& DOUGLAS, A. (2009). Does Size Matter For Six Sigma İmplementation? Findings From the Survey in UK SMEs. The TQM Journal. 21(6):623-635.

KWAK, Y. H., \& I F. T. (2006). Benefits, Obstacles, and Future of Six Sigma Approach. Technovation. 26(5-6): 708-715.

LAUREANI, A. \& ANTONY, J. (2012). Standards for Lean Six Sigma certification. International Journal of Productivity and Performance Management. 61(1), 110120.

NIÑEROLA, A., SÁNCHEZ-REBULL, M. V., \& HERNÁNDEZ-LARA, A. B. (2019). Six Sigma Literature: A Bibliometric Analysis. Total Quality Management $\mathcal{E}$ Business Excellence. 1-22.

ÖZÇELIKKEL, H. (1994). Bir Personel Yöneticisinin Gözüyle: Japon Yönetim Sistemleri. MESS Eğitim Vakfı.

ÖZTÜRK, İ. (2017). Altı Sigma, Yalın Üretim ve Yalın Altı Sigma Metodolojisinin Tarımsal İşletmelerde Verimlilik ve Kalite Üzerine Etkisi. KSÜ Doğa Bilimleri Dergisi. 20(3): 201-208.

PANAGOPOULOS, I., ATKIN, C. J., \& SIKORA, I. (2016). Lean Six-Sigma İn Aviation Safety: An İmplementation Guide For Measuring Aviation System's Safety Performance. Journal of Safety Studies. 2(2): $1-12$.

RAISINGHANI, M.S., ETTE, H., PIERCE, R., CANNON, G. \& DARIPALY, P. (2005). Six Sigma: Concepts, Tools, and Applications. Industrial Management E Data Systems. 105(4): 491-505.

RATHI, R., KHANDUJA, D., \& SHARMA, S. K. (2016). Capacity Waste Management at Automotive Industry in India: A Six Sigma Observation. Acounting. 2(3): 109-116.

SCHROEDER, R. G., LINDERMAN, K., LIEDTKE, C., \& CHOO, A. S. (2008). Six Sigma: Definition and Underlying Theory. Journal of operations Management. 26(4): 536-554.

SINGH, M. \& RATHI, R. (2019), A Structured Review of Lean Six Sigma in Various Industrial Sectors. International Journal of Lean Six Sigma. 10(2): 622-664. 
SNEE, R. D., \& HOERL, R. W. (2003). Leading Six Sigma: a step-by-step guide based on experience with GE and other Six Sigma companies. Ft Press.

SNEE, R.D. (2010), Lean Six Sigma - getting better all the time. International Journal of Lean Six Sigma, 1(1):129.

ŞANTAŞ, G. (2020). Sağlıkta Yalın Yönetim ve Yalın Liderlik. Sağllk ve Hemşirelik Yönetimi Dergisi. 2(7): 323329.

TOPÇU, H., DOĞAN, B., \& DOĞAN, M. (2018) Altı Sigma Yöntemi ve Yükseköğretim Kurumlarında Uygulanabilirliği Üzerine Bir Çalışma. Bartın Üniversitesi Eğitim Araştırmaları Dergisi. 2(1): 68-79.

ULUSKAN, M. (2017). Türkiye'nin Altı Sigma Uygulama Haritası. Çukurova Üniversitesi Mühendislik-Mimarlık Fakültesi Dergisi. 32(3): 131-144.

WOMACK, J. P., \& JONES, D. T. (1994). From Lean Production to the Lean Enterprise. Harvard Business Review. 72(2): 93-103.

WONG, W. P., IGNATIUS, J., \& SOH, K. L. (2014). What is the leanness level of your organisation in lean transformation implementation? An integrated lean index using ANP approach. Production Planning $\mathcal{E}$ Control. 25(4): 273-287.

YALCINER, A. Y., \& GÜNDAY, R. (2020) Yalın Altı Sigma Metodu ve Bankacılık Sektöründe Uygulanması. Düzce Üniversitesi Bilim ve Teknoloji Dergisi. 8(1): 188-209. 